\title{
Relationship between Heart Rate and Oxygen Uptake during Submaximal Arm Cranking in Paraplegics and Quardriplegics
}

\author{
Masanori IrIZAWA ${ }^{1)}$, Masahiro Yamasaki ${ }^{1)}$, Satoshi MURAKI ${ }^{1)}$, Takashi KomUrA ${ }^{1)}$ \\ Kunihiro SEKI ${ }^{2)}$ and Kunio KIKUCHI ${ }^{1)}$
}

1) Department of Health Science, Faculty of Integrated Arts and Sciences, Hiroshima University

2) Department of Biological Science, Faculty of Science, Kanagawa University

\begin{abstract}
The purpose of this study was to clarify the effect of the level of spinal cord injury (SCI) and of daily exercise on the relationship between heart rate (HR) and oxygen uptake $\left(\mathrm{VO}_{2}\right)$ in persons with SCI (PSCI) during an arm cranking exercise. Eighteen PSCI were divided into three groups according to the level of SCI ; 4 quadriplegics (C6-C8), 7 high-level paraplegics (T3-T8), and 7 low-level paraplegics (T10-L2). In the relationship between $\mathrm{HR}$ and $\mathrm{Vo}_{2}$, the higher the level of $\mathrm{SCI}$, the smaller the slope of regression line, that means the $\mathrm{HR}$ at a given $\mathrm{VO}_{2}$ become larger as level of $\mathrm{SCI}$ was higher. Significant differences were found among these regression lines $(P<0.01)$. In addition, the regression lines between $\mathrm{HR}$ and $\mathrm{VO}_{2}$ in active persons tended to shift toward upper in comparion with those in inactive persons. The present investigation clearly shows that the $\mathrm{HR}-\mathrm{Vo}_{2}$ relationship in PSCI is remarkably influenced by the level SCI and physical training.

(Ann. Physiol. Anthrop. 13(5) : 275-280, 1994)
\end{abstract}

Key words : Heart rate, Oxygen uptake, Paraplegics, Quadriplegics, Arm cranking exercise

It has been well established that persons with spinal cord injury (PSCI) have higher heart rate (HR) responses for a given work rate or oxygen uptake $\left(\mathrm{VO}_{2}\right)$ level than able-bodied persons (ABP) (Hjeltnes, 1977; Jehl et al., 1991). The higher HR response during submaximal exercise. could be attributed to venous blood pooling in paralyzed lower limbs that resulted in lower stroke volume. Thus, in PSCI, the relationship between $\mathrm{HR}$ and $\mathrm{VO}_{2}$ is expected to be different from that in ABP.

Furthermore, as the level of spinal cord injury (SCI) is higher, haemodynamic adaptation to exercise will be strongly affected. Drory et al. (1990) pointed out that in exercising at similar work loads, HR was significantly higher in quadriplegics and upper paraplegics (T1-T) than in $\mathrm{ABP}$, and no significant differences were found between lower paraplegics (below T6) and ABP. Even in everyday life, persons with the high level of SCI showed the higher HR (Yamasaki et al., 1992). In the relationship between $\mathrm{HR}$ and $\mathrm{VO}_{2}$, the level of $\mathrm{SCI}$ should be taken into consideration.

As is true with ABP, physically active PSCI have a higher capacity for aerobic exercise compared to inactive PSCI (Nilsson et al., 1975 ; Davis and Shephard, 1988; Yamasaki et al., 1994). It has been widely confirmed that in trained ABP, HR responses for given work load are lower than in untrained ABP. Accordingly, training level is one of the most important factors in the relationship between $\mathrm{HR}$ and $\mathrm{VO}_{2}$. However, there are few studies of training effect on this relationship in PSCI.

Therefore, the purpose of this investigation was 
to clarify the influences of the level of SCI and of daily exercise on the relationship between $H R$ and $\mathrm{VO}_{2}$ in PSCI during arm cranking exercise.

\section{METHODS}

Subjects. The subjects of this study were 18 males with SCI who had resumed their familial or social activities. Of the $18 \mathrm{PSCI}, 4$ were quadriplegics and 14 were paraplegics. Table 1 shows the physical characteristics of PSCI in relation to the level of SCI (4 quadriplegics, C6-C8, 7 high-level paraplegics, T3-T8, and 7 low-level paraplegics, T10 -L2). Ten PSCI comprising of two quadriplegics, four high-level paraplegics, and four low-level paraplegics had regularly engaged in sports (marathon, tennis, weight training, archery, or basketball) at least three times a week. These subjects were defined here as active subjects, and others as inactive subjects.

In addition, 8 male ABP served as control subjects, ranging in age from 20 to 42 years, in body mass from 55 to $75 \mathrm{~kg}$, and in height from 165 to $183 \mathrm{~cm}$. The ABP were also divided into active and inactive group according to their daily lifestyle. None had any cardiopulmonary or metabolic dis. ease. Each subject was informed previous to testing as to the purpose of the study, their extent of involvement, and any known risks. Each expressed understanding by signing a statement of informed consent.
Experimental Protocol. Before exercise, the subjects kept resting in supine position for $30 \mathrm{~min}$ and sitting position on his wheelchair for $15 \mathrm{~min}$. A mechanically braked arm cranking ergometer (Monark Rehab Trainer model 881E) was used at 6 levels of exercise (50 rpm at 0 watts, and 20, 30, 40, 50 and $60 \mathrm{rpm}$ at 30 watts). For quandriplegics, the level of exercise was set at 10 watts instead of 30 watts, taking into account their muscle power. Exercise at each load was $4 \mathrm{~min}$ in duration interspersed by at least $10 \mathrm{~min}$ rest periods. The sequence of the exercises in each subject was randomized. PSCI tended to move the upper half of the body vigorously during exercise. Then, a simple head rest (Fig. 1) was prepared, and its effect was also assessed. The subjects were instructed to fast

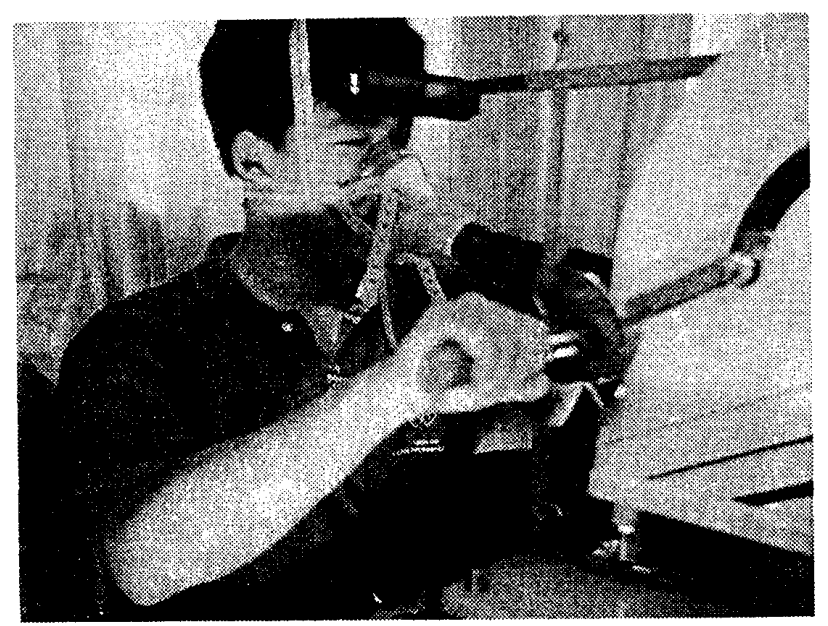

Fig. 1 Subject in position using an arm cranking ergometer with head rest.

Table 1 Physical Characteristics of Subjects

\begin{tabular}{|c|c|c|c|c|c|c|c|c|c|c|c|c|}
\hline \multirow{2}{*}{ Level of Injury } & \multirow{2}{*}{$\mathrm{n}$} & \multirow{2}{*}{$\begin{array}{l}\text { Age } \\
\text { (yrs) }\end{array}$} & \multirow{2}{*}{$\begin{array}{l}\text { Weight } \\
(\mathrm{kg})\end{array}$} & \multirow{2}{*}{$\begin{array}{c}\text { Years in } \\
\text { Wheelchair }\end{array}$} & \multicolumn{4}{|c|}{ Skinfold Thickness (mm) } & \multicolumn{2}{|c|}{ Girth $(\mathrm{cm})$} & \multicolumn{2}{|c|}{ Grip Strength (kg) } \\
\hline & & & & & B & $\mathrm{T}$ & $\mathrm{S}$ & $\mathrm{C}$ & $\mathrm{U}$ & $\mathrm{C}$ & Right & Left \\
\hline \multirow[t]{2}{*}{$\mathrm{C} 6-\mathrm{C} 8$} & 4 & 27.0 & 53.5 & 7.0 & 3.7 & 4.5 & 7.5 & 7.1 & 23.8 & 85.8 & 15.6 & 12.4 \\
\hline & & \pm 6.8 & \pm 7.8 & \pm 7.2 & \pm 1.1 & \pm 2.3 & \pm 2 & \pm 3.2 & \pm 3.4 & \pm 5.2 & \pm 18.7 & \pm 17.5 \\
\hline \multirow[t]{2}{*}{$\mathrm{T} 3-\mathrm{T} 8$} & & 38.4 & 61.2 & 9.2 & $4 . \overline{4}$ & 8.2 & 14.1 & 13.5 & 28.9 & 92.4 & 54.6 & $50 . \overline{9}$ \\
\hline & & \pm 13.3 & \pm 12.6 & \pm 7.8 & \pm 2.3 & \pm 4.2 & \pm 5.7 & \pm 8.6 & \pm 3.9 & \pm 10.6 & \pm 5.6 & \pm 8.2 \\
\hline \multirow[t]{2}{*}{$\mathrm{T} 10-\mathrm{L} 2$} & $\gamma$ & 38.9 & 60.2 & $10 . \overline{7}$ & 4.2 & 7.4 & 13.0 & 12.4 & 30.9 & 96.8 & 54.7 & 50.2 \\
\hline & & \pm 6.8 & \pm 7.8 & \pm 8.2 & \pm 2.6 & \pm 2.1 & \pm 4.2 & \pm 4.5 & \pm 1.7 & \pm 8.4 & \pm 8.5 & \pm 6.3 \\
\hline \multirow[t]{2}{*}{ Total } & 18 & 36.1 & 59.1 & 9.3 & 4.2 & 7.0 & 12.2 & 11.7 & 28.5 & 92.7 & 46.0 & 42.1 \\
\hline & & \pm 10.6 & \pm 9.9 & \pm 7.5 & \pm 2.1 & \pm 3.3 & \pm 5 & \pm 6.5 & \pm 4 & \pm 9.3 & \pm 19.4 & \pm 18.9 \\
\hline
\end{tabular}

Mean \pm standard deviation

B, Biceps; T, Triceps; S, Subscapular; C, Chest; U, Upper arm 
for at least 2 hours before a test. Room temperatures were controlled to the range of 24 to $26^{\circ} \mathrm{C}$.

Physiological Variables. $\mathrm{HR}$ and $\mathrm{VO}_{2}$ were determined during the last 5 minutes in both the supine position and the sitting position on his wheelchair and during the last minute of arm cranking exercise. Expired gas was collected uning a Douglas bag. The volume of expired gas was measured with a dry gas meter. Oxygen and carbon dioxide concentrations in the expired gas were measured with an instantaneous gas analyzer (Respina, NEC-Sanei). The gas analyzer was calibrated before and during testing with room air and reference gases of known concentrations. HR was measured with a telemetric electrocardiograph using the chest lead method.

Statistical Analysis. Regression techniques were employed to examine the relationship between $\mathrm{HR}$ and $\mathrm{Vo}_{2}$. Analysis of covariance was used for statistical comparison of regression lines. The unpaired t-test was utilized to test for differences in the responses of the measured variables between active and inactive subjects. All $P$ values less than 0.05 were considered significant.

\section{RESULTS}

To clarify the relationship between $\mathrm{HR}$ and $\mathrm{VO}_{2}$, we analyzed regression lines of these two parameters determined in the two resting positions. In most subjects, the coefficient of correlation between the two parameters tened to be higher in the supine position than in the sitting position. The values of these parameters in the supine position, therefore, were used as the resting values of the parameters in subsequent analyses.

The influence of the head rest on the relationship between $\mathrm{HR}$ and $\mathrm{VO}_{2}$ was examined (Fig. 1). Fig. 2 compares the regression line using a head rest to that without a head rest in one subject. The movement of the upper half of the body during a given level of exercise became smaller by using a head rest. However, the relationship between $H R$ and $\mathrm{Vo}_{2}$ was hardly affected by the use of this head rest.

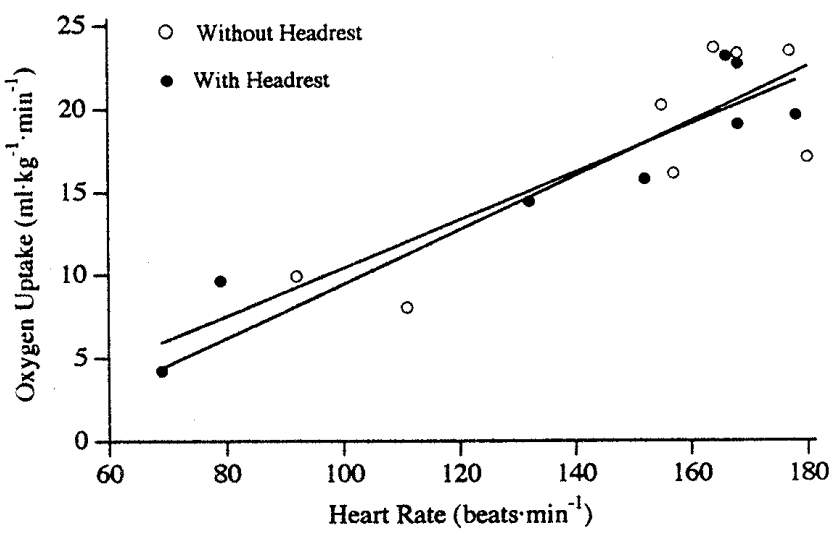

Fig. 2 Example of regression lines for heart rate and oxygen uptake for one subject with and without head rest.

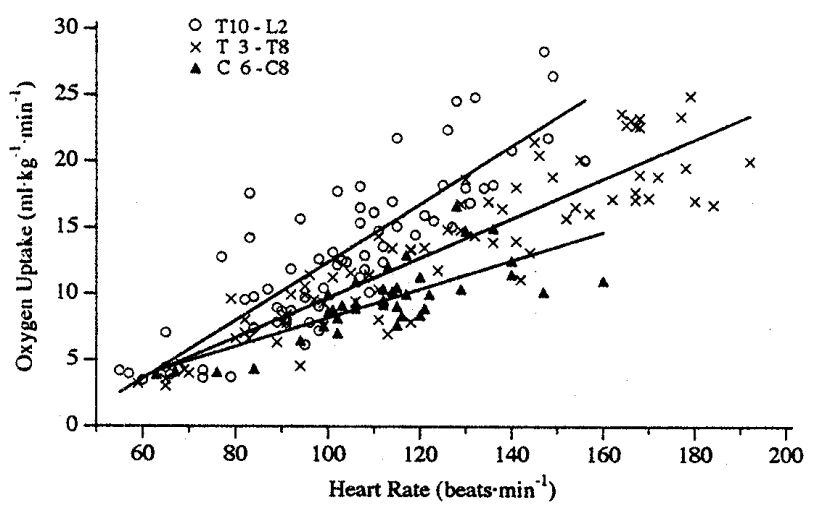

Fig. 3 Relationships between heart rate and oxygen uptake for three groups: quadriplegics (A), high-level paraplegics $(X)$ and low-level paraplegics $(\bigcirc)$.

Even when differences in the level of SCI and the muscle power differences were taken into condideration, the regression line remained almost unchanged irrespective of the use of the head rest. In subsequent analyses, therefore, the data using a head rest were analyzed togethe with the data obtained without a head rest.

Fig. 3 shous the relationship between $\mathrm{HR}$ and $\mathrm{VO}_{2}$ in each of three groups. In each group, the $\mathrm{HR}-\mathrm{VO}_{2}$ relationship was linear, resembling the relationship observed in ABP. The higher the level of SCI, the smaller the slope of regression line. That is, the percent of increase in $\mathrm{HR}$ following a given increase of $\mathrm{VO}_{2}$ become larger as level of SCI was higher. Statistically, there were significant differences among these regression lines $(P<0.01)$. In compari- 
son to $\mathrm{ABP}, \mathrm{HR}$ at same $\mathrm{VO}_{2}$ was significantly higher in quadriplegics and high-level paraplegics, while no differences were found between $\mathrm{ABP}$ and low-level paraplegics.

In general, the regression lineds between HR and $\mathrm{VO}_{2}$ in active persons tended to shift toward upper in comparison with those in inactive persons. Thus, $\mathrm{VO}_{2}$ at a level of $\mathrm{HR}$ will become larger in active persons than inactive persons. Fig. 4 compares the $\mathrm{VO}_{2}$ at a HR of 120 beats $\cdot \mathrm{min}^{-1}$ between active and inactive persons. At this $\mathrm{HR}$ level, $\mathrm{VO}_{2}$ increased in both active and inactive persons as the level of SCI became lower. There were significant differences between the $\mathrm{VO}_{2}$ at a $\mathrm{HR}$ of 120 beats/min in active and inactive persons. Fig. 5 schematically compareds the $\mathrm{HR} \cdot \mathrm{VO}_{2}$ relationship for active and for inactive subjects in each of four groups. In all groups, the gradient of the regression line was higher for active subjects than for inactive subjects. Namely, the percent of increase in HR following a given increase in $\mathrm{VO}_{2}$ was smaller for active subjects in all groups, although the magnitude of this tendency slightly differed among the four groups.

\section{DISCUSSION}

The $\mathrm{HR}-\mathrm{VO}_{2}$ relationship in $\mathrm{ABP}$ has been regarded as a useful index in assessing the respiratory and carciovascular function and the endurance of individuals. In PSCI, the $\mathrm{HR} \cdot \mathrm{VO}_{2}$ relationship has been also widely utilized for prediction of energy expenditure (Mollinger et al., 1985 ; Yamasaki et al., 1992), exercise prescription (Hooker et al, 1993), and prediction of physical work capacity (Irizawa et al., 1991). Consequently, it is significant to clarify characteristics of the $\mathrm{HR}-\mathrm{VO}_{2}$ relationship in PSCI.

As the level of SCI became higher, the slope of the regression line between $\mathrm{HR}$ and $\mathrm{VO}_{2}$ decreased, indicating that the percent increase in $\mathrm{VO}_{2}$ for a given increase in HR was suppressed as the level of SCI. This may be explained by the view that, as the level of SCI becomes higher, the oxygen-consuming active muscles and the muscular pumping action decrease, which leads to a reduction in blood return and to an increase in HR (Bevegard et al., 1966, Pollock et al., Bar-Or et al., 1978). More recently, Hooker et al. (1994) showed that the relationship between percent peak $\mathrm{HR}$ and percent $\mathrm{VO}_{2}$ during arm cranking exercise was not altered in persons with either high or low paraplegics. On the other hand, McLean et al. (1992) reported a complete dissociation of the percent peak $\mathrm{HR}$ and percent $\mathrm{VO}_{2}$ relationship due to the lack of $\mathrm{HR}$ increase during arm cranking exercise in quadriplegics. These studies indicated that even when $\mathrm{HR}$ and $\mathrm{VO}_{2}$ were expressed as percent to respective peak value, this relationship in quadriplegics differ from thatin paraplegics. Droy et al. (1990) pointed out that HR at similar workloads was significantly higher in quadriplegics and higher PSCI than in controls, whereas no differences were observed between lower PSCI and controls. These findings were in good agreement with ours. Droy et al. (1990) condidered that the higher $\mathrm{HR}$ was compensatory mechanism of the low systolic blood pressure in quadriplegics and high-level paraplegics.

The degree of physical training is an important factor in the relationship between the $\mathrm{HR}-\mathrm{VO}_{2}$ relationship in not only $\mathrm{ABP}$ but also PSCI. The present investigation clearly shows how the $\mathrm{HR}-\mathrm{VO}_{2}$ relationship is influenced by physical training. In general, physically active PSCI showed higher peak oxygen uptake than inactive subjects due to training effect (Nilsson et al., 1975 ; Yamasaki et al., 1993, 1994). However, the training effects in PSCI are especially reflected in a drop in HR during submaximal arm exercise (Ekblom and Lundberg, 1968; $Z$ weiren and Bar-Or, 1975). This finding is a remarkably good agreement with our data illustrated in Fig. 4 and 5.

In summary, this study indicates that the $\mathrm{HR} \cdot \mathrm{Vo}_{2}$ relationship in PSCI is affected greatly by the level of SCI and daily habit of exercise, and that the aerobic ability of PSCI at any level can be improved by arm exercise. 


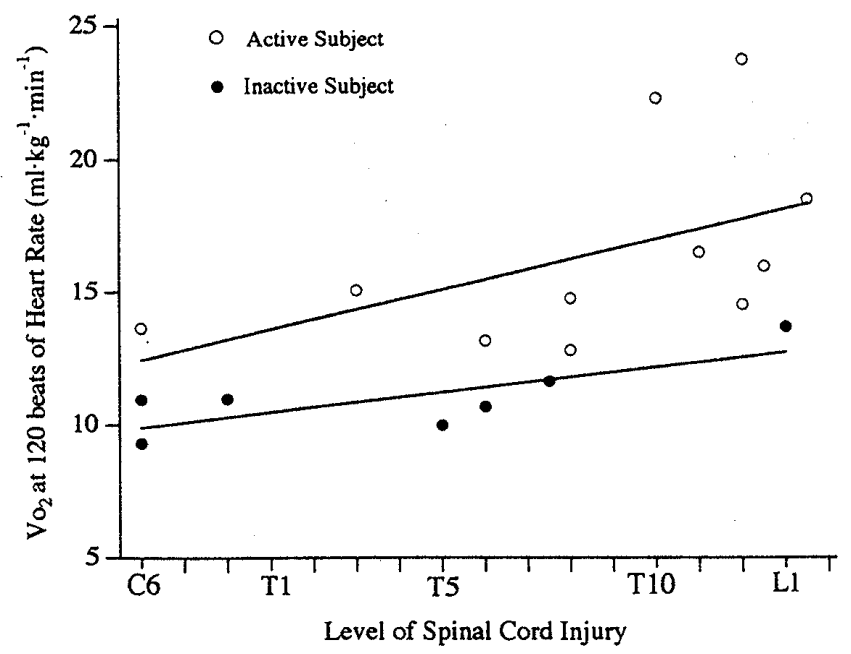

Fig. 4 Relationships between level of spinal cord injury and oxygen uptake $\left(\mathrm{Vo}_{2}\right)$ at 120 beats of heart rate. The trend lines are illustrated. Open circle: active subject. Closed circle : inactive subject.

\section{REFERENCES}

Bar-Or, O., O. Inbar, and R. Spira (1978) ; Physiological effects of a sports rehabilitation program on cerebral palsied and post poliomyelitic adolescents. Med. Sci. Sports, 8 : 157-161

Bevegard, S., U. Freyschuss, and T. Stande 11 (1966) ; Circulatory adaptation to arm and leg exercise in supine and sitting position. J. Appl. Physiol., 21 : 37-46.

Davis, G.M. and R.J. Shephard (1988) ; Cardiorespiratory fitness in highly active versus inactive paraplegics. Med. Sci. Sports Exerc., 20 : 463-468.

Drory, Y., A. Ohry, M.E. Brooks, D. Dolphin, and J. J. Kellermann (1990); Arm crank ergometry in chronic spinal cord injured patients. Arch. Phys. Med. Reabil., 71 : 389-392.

Ekblom, B. and A. Lundberg (1968); Effects of physical training on adolescents with severe motor handicaps. Acta Paed. Scand., 57 : 17-23.

Hjeltnes, N. (1977); Oxygen uptake and carciac output in graded arm exercise in paraplegics with low level spinal lesions. Scand. J. Rehal. Med., 9 : 107-113.

Hooker, S. P., J.D. Greenwood, D.T. Hatae, R.P. Husson, T.L. Matthiesen, and A.R. Waters (1993);

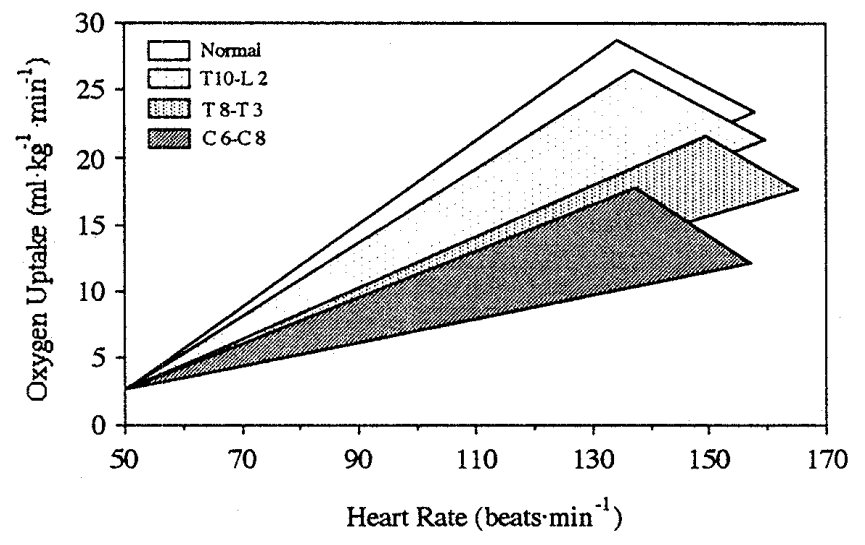

Fig. 5 Schematic illustration of extent of regression lines between active and inactive subjects.

Oxygen uptake and heart rate relationship in persons with spinal cord injury. Med. Sci. Sportsz Exerc., 25: 1115-1119.

Irizawa, M., M. Yamasaki, T. Komura, K. Kikuchi, H. Sasaki, K. Kai, and K. Ohdoko (1991) ; Carciorespiratory responses during arm cranking exercise in spinal cord injured subjects. Proc. of XII Congress of Biomechanism. 135-138, 1991.

Jehl, J.L., M. Gandmontagne, G. Pastene, M. Eyssette, R. Flandrois, and J. Coudert (1991) ; Cardiac output during exercise in paraplegic subjects. Eur. J. Appl. Physiol., 62 : 256-260.

McLean, K.P., P.P. Janes, and J.S. Skinner (1992); Heart rate $/ \mathrm{VO}_{2}$ relationship in exercising quadriplegics. Med. Sci. Sports Exerc., 24 (Suppl.) : S17. Mollinger, L.A., G.B. Spurr, A.Z. El Ghatit, J.J. Barboriak, C.B. Rooney, D.D. Davidoff, and R.D. Bongard (1985); Daily energy expenditure and basal metabolic rates of p1tients with spinal cord injury. Arch. Phys. Med. Rehabil., 66 : 420-426.

Nilsson, S., D.H. Staff, and E.D.R. Pruett (1975); Physical work capacity and the effect of training on subjects with long standing paraplegia. Scand. J. Rehabil. Med., 58 : 467-476.

Pollock, M.L., H.S. Miller, A.C. Linnaud, E. Laughridge, E. Coleman, and E. Alexander (1974); Arm pedaling as endurance training regimen for the disabled. Arch. Phys. Med. Rehabil., 55 : 418-424. Yamasaki, M., M. Irizawa, K. Ishii, and S. Muraki (1994); Effects of sports participation on physical 
and mental condition in persons with spinal cord injury. Descente Sports Sci., 15 : in press.

Yamasaki, M., M. Irizawa, T. Komura, K. Kikuchi, H. Sasaki, K. Kai, and K. Ohdoko (1992) ; Daily energy expenditure in active and inactive persons with spinal cord injury. J. Human Ergol., 21 : 125 $-133$.

Yamasaki, M., Y. Tahara, K. Katsuno, Y. Fukuyama, N. Tsunawake, and K. Fujiie (1993);
Aerobic work capacity in Japanese athletes with spinal cord injury. 9th Inter. Symp. on Adapted Phys. Act., (Abstract), p. 180.

Zwiren, L.D. and O. Bar-Or (1975) ; Responses to exercise of paraplegics who differ in conditioning level. Med. Sci. Sports, 7 : 94-98.

(Recieved March 28, 1994) (Accepted May 10, 1994)
Masanori IRIZAWA

入 澤 雅 典
Department of Health Science, Faculty of Integrated Arts and Sciences, Hiroshima University, 1-7-1 Kagamiyama, Higashi-Hiroshima 724, Japan

F724 東広島市鏡山1-7-1 広島大学総合科学部健康科学教室 